\title{
New insights in the pathogenesis and genetics of leprosy
} Andrea Gulia $^{1}$, Isabella Fried ${ }^{2}$ and Cesare Massone ${ }^{2 *}$

\author{
Addresses: ${ }^{1}$ Department of Dermatology, University of L'Aquila, Via Vetoio - Coppito 2 I-67100, L'Aquila, Italy; ${ }^{2}$ Department of Dermatology, \\ Medical University of Graz, Auenbruggerplatz 8, A-8036, Graz, Austria \\ * Corresponding author: Cesare Massone (cesare.massone@klinikum-graz.at) \\ FI000 Medicine Reports 2010, 2:30 (doi:I0.3410/M2-30)
}

The electronic version of this article is the complete one and can be found at: http://fl000.com/reports/medicine/content/2/30

\begin{abstract}
In the last 30 years the leprosy burden has been dramatically reduced but over the last 5 years still more than 200,000 new cases were detected each year. Advances in immunology, pathogenesis, and genetics of leprosy have been reported. A deeper understanding of the mechanisms of infection will ultimately improve our ability to fight against this potentially devastating infectious disease.
\end{abstract}

\section{Introduction and context}

Leprosy is a human chronic infectious disease caused by Mycobacterium leprae. It affects the skin and peripheral nerves and can cause irreversible impairment of nerve function and consequent chronic disabilities. Only a small percentage (less than $1 \%$ ) of the population that comes into contact with $M$. leprae will develop the disease [1]. Since the introduction of multidrug therapy in 1982 by the World Health Organisation the leprosy burden has been dramatically reduced, but over the last 5 years more than 200,000 new detected cases were still being reported each year $[1,2]$.

The hallmark of leprosy is a broad clinical spectrum of pathology determined by the host immune response. Tuberculoid (TT) leprosy patients mount a vigorous T-helper 1 (Th1) cell-mediated immune response in skin and nerves, displaying a delayed-type hypersensitivity response to $M$. leprae antigens. Although limiting the number of bacilli and lesions, this strong response accounts for the prominent impairment of the peripheral nerves [1]. Conversely, lepromatous (LL) leprosy patients exhibit specific cellular unresponsiveness to M. leprae antigens associated with a T-helper 2 (Th2) immune response and high mycobacterial loads in the skin and nerves. However, most leprosy patients display a pathogenesis between the two polar forms and are classified as either borderline tuberculoid or borderline lepromatous. Leprosy reactions are common in these immunologically unstable borderline groups and involve an upregulation of the host response to M. leprae antigens $[1,2]$. In patients with the disseminated form, lepromatous leprosy, a reaction known as erythema nodosum leprosum (ENL) is frequent, being observed in up to $50 \%$ of lepromatous leprosy patients receiving antimicrobial therapy $[1,2]$.

Research into the mechanisms underlying infection, pathogenesis, and clinical sequelae has been limited by the fact that M. leprae infects only humans and cannot be cultured in vitro. However, the complete sequence of the genome of $M$. leprae was published at the beginning of the 21st century [3]. Today, accumulated evidence clearly indicates that exposure to $M$. leprae is necessary but not sufficient to explain susceptibility to leprosy, and several genes and genomic regions have been implicated as players in the complex genetic mechanism controlling host susceptibility to the disease [1].

\section{Recent advances} Immune response

An effective innate immune response in combination with the low virulence of the leprosy bacillus may underlie resistance to the development of clinical disease. Dendritic cells (DCs) uptake M. leprae and subsequent local production of cytokines and chemokines regulates inflammation and influences the course of the adaptive cell-mediated immunity into a Th1 or 
Th2 response. Although DCs are known to be effective presenters of $M$. leprae antigens, major histocompatibility complex (MHC) class I and II expression is downregulated in monocyte-derived DCs infected with M. leprae bacilli. On the other hand, DCs stimulated with M. leprae membrane antigens upregulate both MHC class II and CD40 ligand-associated interleukin-12 (IL-12) production, suggesting that whole live bacilli may suppress the interaction of DCs and T cells [4].

The cytokine profile present in the lesion also appeared to be correlated with Toll-like receptor (TLR) function: Th1type cytokines are associated with TLR1 and TLR2 activation, and Th2-type cytokines are associated with inhibition of activation. The expression of TLR1 and TLR2 has been found to be stronger on monocytes and DCs in TT lesions than in the LL counterparts. In addition, in vitro studies showed that the M. leprae $19-\mathrm{kDa}$ and $33-\mathrm{kDa}$ lipoproteins could activate monocytes and monocytederived DCs through TLR2 [5].

Recent investigations showed that plasmacytoid DCs are not involved in the immune response against M. leprae whereas FoxP3-positive cells (markers of regulatory T cells, or $\mathrm{T}_{\text {reg }}$ cells) were present in $95 \%$ of the cases in a retrospective immunohistochemical study, with an average density of $2.9 \%$ of the infiltrate. Their distribution was not related to granulomatous structures or special locations [6].

\section{Helminthic co-infection and leprosy}

Since similar investigations in tuberculosis, a significant association between intestinal helminthic infections and multibacillary leprosy has also been reported $[7,8]$. Intestinal helminths are known to elicit a strong systemic Th2-type response, which is normally followed by a reduction in Th1-type immunity. It is possible that the presence of intestinal helminths downregulates the required Th1-type immunity via upregulation of Th2type cytokine production, facilitating a subsequent infection by M. leprae. Evidence that Th1 downmodulation occurs during intestinal helminth infection was provided by the fact that intracellular interferon-gamma (IFN- $\gamma$ ) levels in both tuberculoid and lepromatous, helminth-free leprosy patients were approximately twofold higher than in helminth-infected leprosy patients. Conversely, lepromatous patients harboring intestinal helminths produced close to twofold more IL-4 and IL-10 than helminth-free leprosy patients [8].

Diniz and colleagues [9] recently reported a significant association between intestinal helminth infections and lepromatous leprosy and observed that the frequency of intestinal helminths correlated strongly with the mycobacterial index. Again, intracellular levels of IFN- $\gamma$ were significantly decreased in leprosy patients co-infected with intestinal helminths when compared with leprosy patients without worms. Conversely, lepromatous leprosy patients with intestinal worms produced higher levels of both IL-4 and IL-10. Results suggest and confirm that a pre-existing infection by intestinal helminths may facilitate the establishment of $M$. leprae infection or its progression to a more severe form of leprosy [9].

\section{Alternative mechanisms of infection}

Recent work has suggested that the successful infection and survival of $M$. leprae could be associated with the ability of M. leprae to regulate cytokine production or to drive Th1 or Th2 responses. Other pathways like insulinlike growth factor could be implicated [10]. Lipid droplet (LD) formation and prostaglandin $2\left(\mathrm{PGE}_{2}\right)$ production are directly correlated, indicating that $M$. leprae-induced LDs constitute intracellular sites for eicosanoid synthesis and that foamy cells may be critical regulators in subverting the immune response in leprosy [11].

\section{Neutrophil recruitment}

One of the histological differences between ENL and lepromatous leprosy is the characteristic infiltration of neutrophils in ENL lesions. Lee and colleagues [12] investigated the mechanisms of neutrophil recruitment at the site of disease. The gene expression profile of ENL lesions comprised an integrated pathway of TLR2 and Fc receptor activation, neutrophil migration, and inflammation. Major aspects of this pathway include the following: (a) FcR or TLR2 induction of IL-1b release; (b) endothelial activation, including the upregulation of E-selectin and subsequent neutrophil binding; and (c) upregulation of inflammatory mediators associated with both neutrophils and monocytes/macrophages. Thalidomide, which is a highly effective agent used in the treatment of ENL and is known to reduce neutrophil infiltration in lesions, targeted individual events in this inflammatory pathway [12].

\section{Biomarkers}

Comparative analysis of serum proteome of leprosy patients by two-dimensional electrophoresis followed by mass spectrometry showed differential expression of acute-phase protein alpha-1-acid glycoprotein (AGP). AGP levels in untreated ENL cases were significantly higher when compared with lepromatous leprosy. After treatment with thalidomide, the levels of AGP decreased to normal levels [13].

\section{Leprosy genes and genomic loci}

Studies indicate that leprosy pathogenesis is a two-step process in which a group of genes controls susceptibility 
to infection per se while different genes control the clinical manifestation of disease. Recent evidence suggests the existence of a third set of genes influencing the development, in a proportion of affected individuals, of leprosy reversal reaction type 1 (RR1).

Concerning human leukocyte antigen (HLA) genes, a strong association has been described between leprosy and HLA-DRB1, HLA-DQA, HLA-linked genes (such as TAP, MICA, and MICB), and two microsatellite markers of the tumor necrosis factor-alpha (TNFA) gene located in the HLA region. Nonetheless, a positive association between leprosy and alleles of HLA-linked genes must be interpreted with caution due to the linkage disequilibrium phenomenon [14-17].

Numerous non-HLA variants located in different genes, such as the vitamin $\mathrm{D}$ receptor (VDR), the natural resistance-associated macrophage protein 1 (NRAMP1), the IL-10, and the PARK2/PACRG genes, have been described as leprosy genetic risk factors. Two singlenucleotide polymorphisms (SNPs) located at the regulatory region shared by the PARK2 and PACRG genes at chromosomal region 6q25-q27 were found to be independently associated with leprosy susceptibility per $s e$ in both a Vietnamese and a Brazilian population [1820]. The chromosomal region 10p13 has been linked to paucibacillary leprosy in two independent studies. The MRC1 gene, encoding the human mannose receptor, is located in the 10p13 region, and nonsynonymous SNPs in exon 7 of the gene have been suggested as leprosy susceptibility factors. Alter and colleagues [21] determined that G396S is the only nonsynonymous exon 7 encoded polymorphism after studying 396 unrelated Vietnamese subjects.

A recent genome-wide study observed a significant association between SNPs in the genes CCDC122, C13orf31, NOD2, TNFSF15, HLA-DR, and RIPK2 and a trend toward an association with an SNP in LRRK2. The associations between the SNPs in C13orf31, LRRK2, NOD2, and RIPK2 and multibacillary leprosy were stronger than the associations between these SNPs and paucibacillary leprosy [22]. Another interesting aspect of the study is that variation in some of the implicated genes is known to be associated with bowel inflammatory conditions. A frame-shift mutation in NOD2 has been identified as a strong susceptibility factor for Crohn's disease. Likewise, variants of TNFSF15 and IL-12B have been associated with Crohn's disease. These findings are consistent with studies of mouse models that have also established a role for Nod2, Ripk2, and Nfkb in intestinal homeostasis and colitis. Together, these studies establish a strong genetic and functional link between susceptibility to leprosy and predisposition to Crohn's disease [22,23]. Alleles of an SNP and a microsatellite marker of the TLR2 gene were the first genetic variants associated with protection and susceptibility to RR1, respectively. Two subsequent reports demonstrated an impact of TLR1 gene variants over the risk of occurrence of RR1 [24,25].

Variability and phylogeography of Mycobacterium leprae New opportunities for understanding the transmission of $M$. leprae and its phylogeny have arisen following the determination of the complete genome sequence by the group led by Stewart Cole [26]. A notable feature of the M. leprae genome is the exceptionally large number of pseudogenes, which occupy almost half of the genome. Initial analysis of SNPs demonstrated that genetic variability between different isolates of $M$. leprae was very rare. Furthermore, all extant isolates of $M$. leprae were nearly indistinguishable, belonging to one of only four SNP types, and are derived from a single clone [26]. Monot and colleagues [26] recently described the complete genome sequence and comparative analysis of a Brazilian strain of M. leprae, Br4923, which was compared with the genomes of strains from North America, Thailand, and India. Monot and colleagues discovered that the four strains share $99.995 \%$ sequence identity. These results are consistent with the hypothesis that leprosy has arisen from infection with a single clone that has passed through a recent evolutionary bottleneck. Differences were found in only 215 polymorphic sites, mainly SNPs, and in 5 pseudogenes. Sixteen interrelated SNP subtypes were defined by genotyping both extant and extinct strains of M. leprae from around the world. The 16 SNP subtypes showed a strong geographical association that reflects the migration patterns of early humans and trade routes, with the Silk Road linking Europe to China having contributed to the spread of leprosy [26].

\section{Implications for clinical practice}

Leprosy forms a spectrum of clinical manifestations that correlate with the immune response to the pathogen, M. leprae. This spectrum is dynamic, with patients developing immune reactions. Leprosy can be seen as a model of a number of phenotypes, ranging from other infectious diseases to several aspects of the immune response.

In terms of the diagnosis, treatment, and prevention of leprosy, the finding that four strains of M. leprae from widely separated countries have genomes that are 99.995\% identical is extremely encouraging. These data mean that antigenic drift in $M$. leprae should be negligible and that the sequences of drug targets will 
not vary. Moreover, genomic studies have allowed investigators to understand the phylogeography of M. leprae.

In the future, biomarkers for reactional stages could aid in early diagnosis, efficient treatment, prevention of neurological complications, and prediction of predisposition to reactional stages. Validation of AGP as an ENL-specific biomarker and treatment indicator has to be confirmed.

The significant association between the presence of intestinal helminths and multibacillary leprosy suggests and supports the implementation of antihelminthic strategies in endemic areas, and this may improve general health and reduce the burden of mycobacterial infections. Further studies on this issue have to be conducted.

The description of the pathogenesis and the genetic basis of susceptibility to leprosy may lead to better protocols for diagnosis, treatment, and prevention of disease. Clinicians will not yet reap benefits from the genetic studies or from the advances in immunopathogenesis of leprosy as described above. At the moment, no changes to clinical practice can be recommended. The hope is that a deeper understanding of the mechanisms of infection will ultimately improve our ability to fight against a potentially devastating infectious disease.

\section{Abbreviations}

AGP, alpha-1-acid glycoprotein; DC, dendritic cell; ENL, erythema nodosum leprosum; HLA, human leukocyte antigen; IFN- $\gamma$, interferon-gamma; IL, interleukin; LD, lipid droplet; LL, lepromatous; MHC, major histocompatibility complex; RR1, reversal reaction type 1; SNP, single-nucleotide polymorphism; Th1, T-helper 1; Th2, T-helper 2; TLR, Toll-like receptor; TT, tuberculoid.

\section{Competing interests}

The authors declare that they have no competing interests.

\section{References}

I. Massone C, Nunzi E: Leprology. Bologna: AIFO; 2009.

2. Scollard DM, Adams LB, Gillis TP, Krahenbuhl JL, Truman RW, Williams DL: The continuing challenges of leprosy. Clin Microbiol Rev 2006, 19:338-81.

3. Cole ST, Eiglmeier K, Parkhill J, James KD, Thomson NR, Wheeler PR, Honoré N, Garnier T, Churcher C, Harris D, Mungall K, Basham D, Brown D, Chillingworth T, Connor R, Davies RM, Devlin K, Duthoy S, Feltwell T, Fraser A, Hamlin N, Holroyd S, Hornsby T, Jagels K, Lacroix C, Maclean J, Moule S, Murphy L, Oliver K, Quail MA, et al.: Massive gene decay in the leprosy bacillus. Nature 200I, 22: $1007-11$.
4. Maeda Y, Gidoh M, Ishii N, Mukai C, Makino M: Assessment of cell mediated immunogenicity of Mycobacterium leprae-derived antigens. Cell Immunol 2003, 222:69-77.

5. Krutzik SR, Ochoa MT, Sieling PA, Uematsu S, Ng YW, Legaspi A, Liu PT, Cole ST, Godowski PJ, Maeda Y, Sarno EN, Norgard MV, Brennan PJ, Akira S, Rea TH, Modlin RL: Activation and regulation of Toll-like receptors 2 and I in human leprosy. Nat Med 2003, 9:525-32.

FI000 Factor 3.0 Recommended

Evaluated by Emanuela Handman 28 May 2003

6. Massone C, Nunzi E, Ribeiro-Rodrigues R, Talhari C, Talhari S, Schettini AP, Parente JN, Brunasso AM, Puntoni M, Clapasson A, Noto S, Cerroni L: T Regulatory Cells and Plasmocytoid Dentritic Cells in Hansen Disease: A New Insight Into Pathogenesis? Am J Dermatopathol 2010, [Epub ahead of print].

7. Resende Co T, Hirsch CS, Toossi Z, Dietze R, Ribeiro-Rodrigues R: Intestinal helminth co-infection has a negative impact on both anti-Mycobacterium tuberculosis immunity and clinical response to tuberculosis therapy. Clin Exp Immunol 2007, | 47:45-52.

\section{Changes Clinical Practice}

FI000 Factor 3.0 Recommended

Evaluated by Nur Alam 26 Sep 2007

8. Diniz LM, Zandonade E, Dietze R, Pereira FE, Ribeiro-Rodrigues R: Short report: do intestinal nematodes increase the risk for multibacillary leprosy? Am J Trop Med Hyg 200I, 65:852-4.

9. Diniz LM, Magalhães EF, Pereira FE, Dietze R, Ribeiro-Rodrigues R: Presence of intestinal helminthes decreases $T h I$ responses in tuberculoid leprosy patients and may increase the risk for multibacillary leprosy. Clin Exp Immunol, in press.

10. Rodrigues LS, da Silva Maeda E, Moreira ME, Tempone AJ, Lobato LS, Ribeiro-Resende VT, Alves L, Rossle S, Lopes UG, Pessolani MC: Mycobacterium leprae induces insulin-like growth factor and promotes survival of Schwann cells upon serum withdrawal. Cell Microbiol 2010, I 2:42-54.

II. Mattos KA, D'Avila H, Rodrigues LS, Oliveira VG, Sarno EN, Atella GC, Pereira GM, Bozza PT, Pessolani MC: Lipid droplet formation in leprosy: Toll-like receptor-regulated organelles involved in eicosanoid formation and Mycobacterium leprae pathogenesis. J Leukoc Biol 2010, 87:37I-84.

12. Lee DJ, Li H, Ochoa MT, Tanaka M, Carbone RJ, Damoiseaux R, Burdick A, Sarno EN, Rea TH, Modlin RL: Integrated pathways for neutrophil recruitment and inflammation in leprosy. J Infect Dis 2010, 201:558-69.

13. Gupta N, Shankernarayan NP, Dharmalingam K: alphal-acid glycoprotein as a putative biomarker for monitoring the development of the type II reactional stage of leprosy. J Med Microbiol 2010, 59:400-7.

14. Alter A, Alcaïs A, Abel L, Schurr E: Leprosy as a genetic model for susceptibility to common infectious diseases. Hum Genet 2008 , 123:227-35.

15. Mira MT: Genetic host resistance and susceptibility to leprosy. Microbes Infect 2006, 8: I I24-3I.

16. Mira MT, Alcais A, di Pietrantonio T, Thuc NV, Phuong MC, Abel L, Schurr E: Segregation of HLA/TNF region is linked to leprosy clinical spectrum in families displaying mixed leprosy subtypes. Genes Immun 2003, 4:67-73.

FI000 Factor 3.0 Recommended Evaluated by Terri Beaty 06 Oct 2003

17. Alcaïs A, Alter A, Antoni G, Orlova M, Nguyen VT, Singh M, Vanderborght PR, Katoch K, Mira MT, Vu HT, Ngyuen TH, Nguyen NB, Moraes M, Mehra N, Schurr E, Abel L: Stepwise replication identifies a low-producing lymphotoxin-[alpha] allele as a major risk factor for early-onset leprosy. Nat Genet 2007, 39:517-22

18. Alcaïs A, Sanchez FO, Thuc NV, Lap VD, Oberti J, Lagrange PH, Schurr E, Abel L: Granulomatous reaction to intradermal injection of lepromin (Mitsuda reaction) is linked to the 
human NRAMPI gene in Vietnamese leprosy sibships. J Infect Dis 2000, 181:302-8.

19. Pereira AC, Brito-de-Souza VN, Cardoso CC, Dias-Baptista IM, Parelli FP, Venturini J, Villani-Moreno FR, Pacheco AG, Moraes MO: Genetic, epidemiological and biological analysis of interleukin-10 promoter single-nucleotide polymorphisms suggests a definitive role for $-819 \mathrm{C} / \mathrm{T}$ in leprosy susceptibility. Genes Immun 2009, 10:174-80.

20. Mira MT, Alcaïs A, Nguyen VT, Moraes MO, Di Flumeri C, Vu HT, Mai CP, Nguyen TH, Nguyen NB, Pham XK, Sarno EN, Alter A, Montpetit A, Moraes ME, Moraes JR, Doré C, Gallant C], Lepage P, Verner A, Van De Vosse E, Hudson TJ, Abel L, Schurr E: Susceptibility to leprosy is associated with PARK2 and PACRG. Nature 2004, 427:636-40.

FI000 Factor 3.0 Recommended

Evaluated by Terri Beaty 0I Apr 2005

21. Alter A, de Léséleuc L, Van Thuc N, Thai VH, Huong NT, Ba NN, Cardoso CC, Grant AV, Abel L, Moraes MO, Alcaïs A, Schurr E: Genetic and functional analysis of common MRCI exon 7 polymorphisms in leprosy susceptibility. Hum Genet 2010, 127:337-48.

22. Zhang FR, Huang $W$, Chen SM, Sun LD, Liu H, Li Y, Cui Y, Yan XX, Yang HT, Yang RD, Chu TS, Zhang C, Zhang L, Han JW, Yu GQ, Quan C, Yu YX, Zhang Z, Shi BQ, Zhang LH, Cheng H, Wang CY,
Lin Y, Zheng HF, Fu XA, Zuo XB, Wang Q, Long H, Sun YP, Cheng YL, et al.: Genomewide association study of leprosy. $N$ Engl J Med 2009, 361:2609-18.

FI000 Factor 6.0 Must Read

Evaluated by Satish Keshav 16 Mar 2010

23. Schurr E, Gros P: A common genetic fingerprint in leprosy and Crohn's disease? N Engl J Med 2009, 36 I:2666-8.

24. Bochud PY, Hawn TR, Siddiqui MR, Saunderson P, Britton S, Abraham I, Argaw AT, Janer M, Zhao LP, Kaplan G, Aderem A: Toll-like receptor 2 (TLR2) polymorphisms are associated with reversal reaction in leprosy. J Infect Dis 2008, 197:253-6I.

25. Misch EA, Macdonald M, Ranjit C, Sapkota BR, Wells RD, Siddiqui MR, Kaplan G, Hawn TR: Human TLRI deficiency is associated with impaired mycobacterial signaling and protection from leprosy reversal reaction. PLoS Negl Trop Dis 2008, 2:e23I.

26. Monot M, Honoré N, Garnier T, Zidane N, Sherafi D, PanizMondolfi A, Matsuoka M, Taylor GM, Donoghue HD, Bouwman A, Mays S, Watson C, Lockwood D, Khamispour A, Dowlati Y, Jianping S, Rea TH, Vera-Cabrera L, Stefani MM, Banu S, Macdonald M, Sapkota BR, Spencer JS, Thomas J, Harshman K, Singh P, Busso P, Gattiker A, Rougemont J, Brennan PJ, et al: Comparative genomic and phylogeographic analysis of Mycobacterium leprae. Nat Genet 2009, 41:1282-9. 